Review Article

\title{
Recent Development in Ammonia Stripping Process for Industrial Wastewater Treatment
}

\author{
Lennevey Kinidi $\left(\mathbb{D},{ }^{1}\right.$ Ivy Ai Wei Tan ${ }^{(D)}{ }^{1}$ Noraziah Binti Abdul Wahab, ${ }^{1}$ \\ Khairul Fikri Bin Tamrin $\mathbb{D}^{2}{ }^{2}$ Cirilo Nolasco Hipolito, ${ }^{1}$ and Shanti Faridah Salleh ${ }^{1}$ \\ ${ }^{1}$ Department of Chemical Engineering and Energy Sustainability, Faculty of Engineering, Universiti Malaysia Sarawak, \\ 94300 Kota Samarahan, Sarawak, Malaysia \\ ${ }^{2}$ Department of Mechanical and Manufacturing, Faculty of Engineering, Universiti Malaysia Sarawak, 94300 Kota Samarahan, \\ Sarawak, Malaysia
}

Correspondence should be addressed to Lennevey Kinidi; lennybb93@outlook.com

Received 5 March 2018; Revised 14 May 2018; Accepted 13 June 2018; Published 9 July 2018

Academic Editor: Sébastien Déon

Copyright (c) 2018 Lennevey Kinidi et al. This is an open access article distributed under the Creative Commons Attribution License, which permits unrestricted use, distribution, and reproduction in any medium, provided the original work is properly cited.

It is noteworthy to highlight that ammonia nitrogen contamination in wastewater has been reported to pose a great threat to the environment. This conventional method of remediating ammonia nitrogen contamination in wastewater applies the packed bed tower technology. Nevertheless, this technology appears to pose several application issues. Over the years, researchers have tested various types of ammonia stripping process to overcome the shortcomings of the conventional ammonia stripping technology. Along this line, the present study highlights the recent development of ammonia stripping process for industrial wastewater treatment. In addition, this study reviews ammonia stripping application for varied types of industrial wastewater and several significant operating parameters. Furthermore, this paper discusses some issues related to the conventional ammonia stripper for industrial treatment application. Finally, this study explicates the future prospects of the ammonia stripping method. This review, hence, contributes by enhancing the ammonia stripping treatment efficiency and its application for industrial wastewater treatment.

\section{Introduction}

Human activities appear to be the major contributor to water pollution, for instance, agricultural, industrial, and municipal activities. Nitrogen surplus released into the environment has been proven to cause negative impacts on water qualities, human health, and ecosystems [1]. Nonetheless, a wide range of technologies is available to reduce the release of ammonia nitrogen into the environment, such as ammonia stripping [2], breakpoint chlorination [3], ion exchange [4], electrodialysis [5], and biological nitrification [6]. The ammonia stripping method has several plus points as it is a relatively simple process and cost-effective to remove ammonia in wastewater [7]. Besides, the valuable ammonia stripped from wastewater can be recovered from the stripping process. Due to the stability of this process, the ammonia stripping process has been deemed as an appropriate method in remediating wastewater that contains high concentration of ammonia and toxic compounds [8]. Consequently, ammonia stripping has emerged as a strong interest research area among researchers and industrial community. As such, numerous labscale and pilot-scale studies have been performed, especially for the wide range of industrial wastewater that demands costeffective remediation.

This paper looks into several emerging issues pertaining to remediating ammonia nitrogen by using the ammonia stripper technique, along with some significant operating parameters. In addition, this paper reviews the recent progress in ammonia stripping method with advanced gas-liquid contactors, as conducted by some researchers. Next, a comparison was made between the advanced liquid contactors and the conventional packed tower. Finally, this paper explores the future prospects of this ammonia stripping process.

\section{Ammonia Stripping Process}

The ammonia stripping process is based on the principle of mass transfer. It is a process, by which wastewater is contacted 


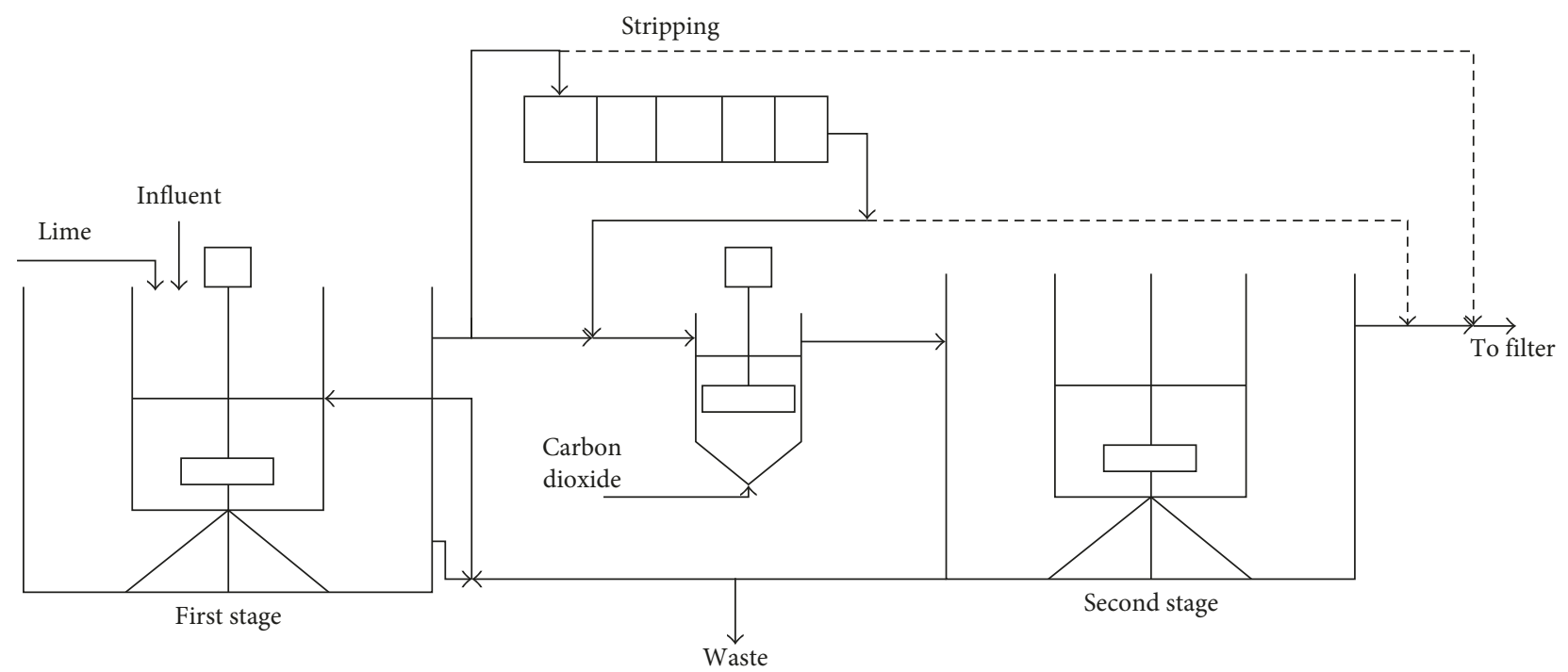

Figure 1: Schematic ammonia stripping process for leachate-polluted groundwater [10].

with air to strip the ammonia gas present in the wastewater. The presence of ammonia in wastewater can be found in two forms, namely, ammonium ions and ammonia gas. The relative concentrations of ammonia gas and ammonium ions are subjected to the $\mathrm{pH}$ and the temperature of wastewater [9]. The formation of ammonia gas is favored by increasing the $\mathrm{pH}$, which shifts the chemical equilibrium to the right, thus inducing the formation of ammonia gas. Since high $\mathrm{pH}$ is required for effective ammonia stripping, lime is used to increase the $\mathrm{pH}$ values of wastewater prior to ammonia stripping [9]. In fact, various types of configurations for ammonia stripping process have been applied to remediate the varied types of wastewater containing ammonia nitrogen. For instance, O'Farell et al. conducted a study on nitrogen removal by stripping on a secondary effluent of a municipal wastewater treatment plant [10]. Figure 1 illustrates a schematic diagram of lime precipitation process and ammonia stripping process. Lime is incorporated to hike the $\mathrm{pH}$ of the influent prior to stripping, and this is followed by a recarbonation process for neutralization. Aside from raising the wastewater $\mathrm{pH}$, calcium oxide (lime) generates calcium carbonate in the wastewater and serves as a coagulant for hard and particulate matters. Additionally, O'Farell et al. discovered that the ammonia stripping method could remove as much as $90 \%$ of ammonia from the secondary effluent [10].

Meanwhile, Raboni et al. investigated the efficiency of the ammonia stripping technique for remediation of groundwater polluted with leachate [11] (Figure 2). In the study, polyelectrolyte, sodium hydroxide, and iron (iii) chloride were added for the coagulation-flocculation and sedimentation processes at $\mathrm{pH}$ higher than 11 [11]. The system also comprised of a heater to heat the wastewater at $38^{\circ} \mathrm{C}$ and ammonia recovery via absorption with sulphuric acid. Lastly, the effluent was neutralized after adding sulphuric acid. As a result, they found that the ammonia stripping system for groundwater polluted with leachate displayed removal efficiency of $95.4 \%$ with initial ammonia concentration at $199.0 \mathrm{mg} / \mathrm{L}$.
Next, Saracco and Genon investigated the performance of air-stripping system to treat ammonia nitrogen from industrial effluent (Figure 3) [12]. They suggested this route as feasible only if the industrial effluent was characterized by relatively high temperature and ammonia concentration. The stripping process was followed by absorption and crystallization processes. Saracco and Genon concluded that the ammonia stripping and the recovery system, along with its internal air recycle, had been technically feasible and easy to control [12].

\section{Ammonia Stripping Application in Industrial Wastewater Treatment}

To date, ammonia stripping pilot-plants have been employed to treat various types of wastewater containing high concentrations of ammonia and toxic compounds, such as that derived from secondary effluent of municipal wastewater treatment plant [10], animal manure [13], and landfill leachate [14]. Most recently, ammonia stripping was applied to anaerobic-digested effluent as this method offers both economic and environmental advantages. The biogas produced in the anaerobic digestion was used for ammonia removal to prevent inhibition of methanogenesis in the anaerobic reactor [15-17]. Meanwhile, Bonmati and Flotats revealed that no $\mathrm{pH}$ modification was required for stripping of ammonia from pig slurry [18]. On the other hand, Limoli et al. investigated ammonia removal from raw manure digestate by employing the turbulent mixing stripping process. They found that the ammonia stripping process via turbulent mixing was indeed feasible for raw manure digestate [19].

Table 1 shows that the ammonia stripping technique is indeed highly efficient in treating wastewater that contains ammonia nitrogen with toxic compounds. Besides, ammonia stripping combined with anaerobic digestion seemed to enhance the performance of anaerobic digestion process, apart from being cost-effective for ammonia removal. 


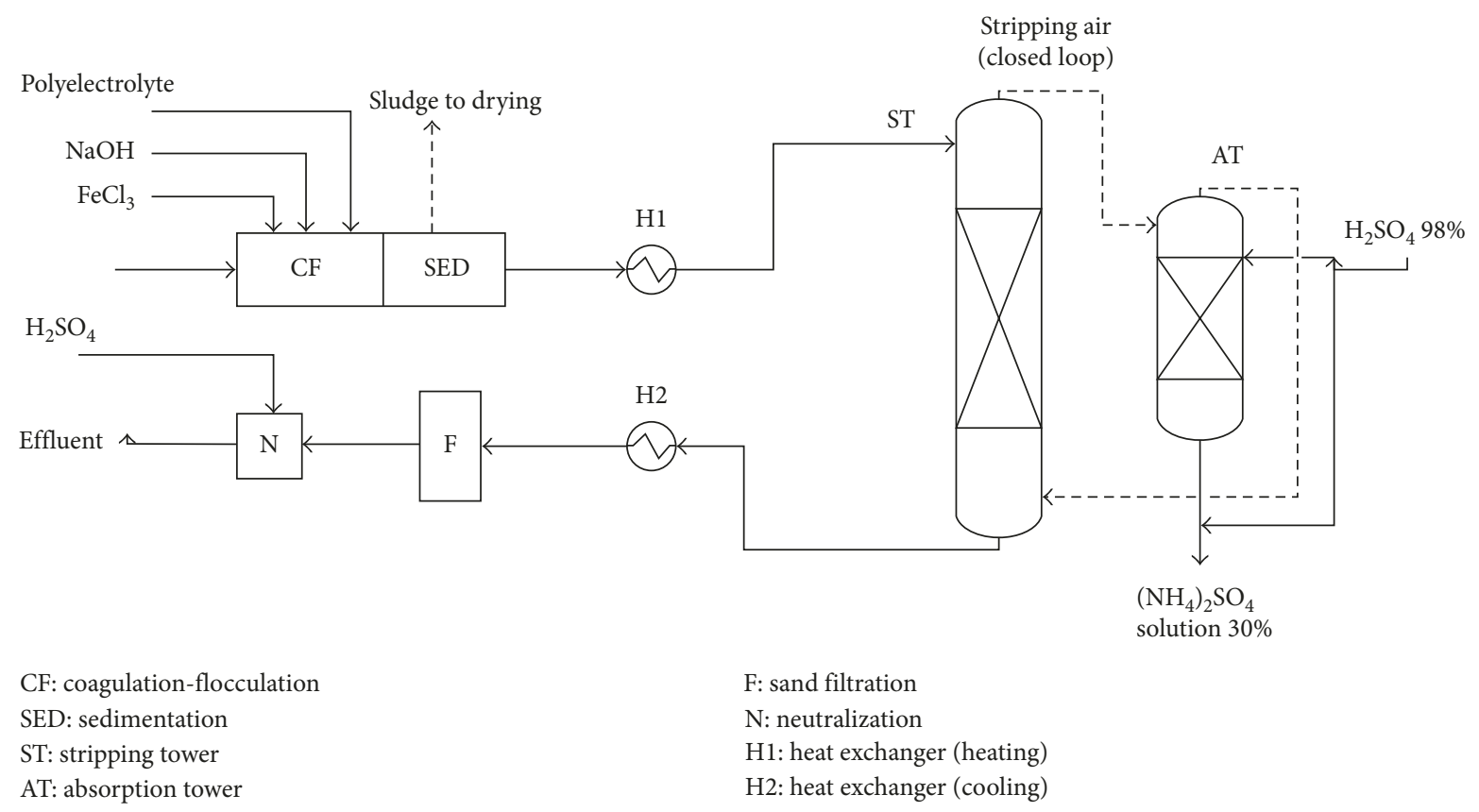

FIGURE 2: Schematic ammonia stripping process for leachate-polluted groundwater [11].

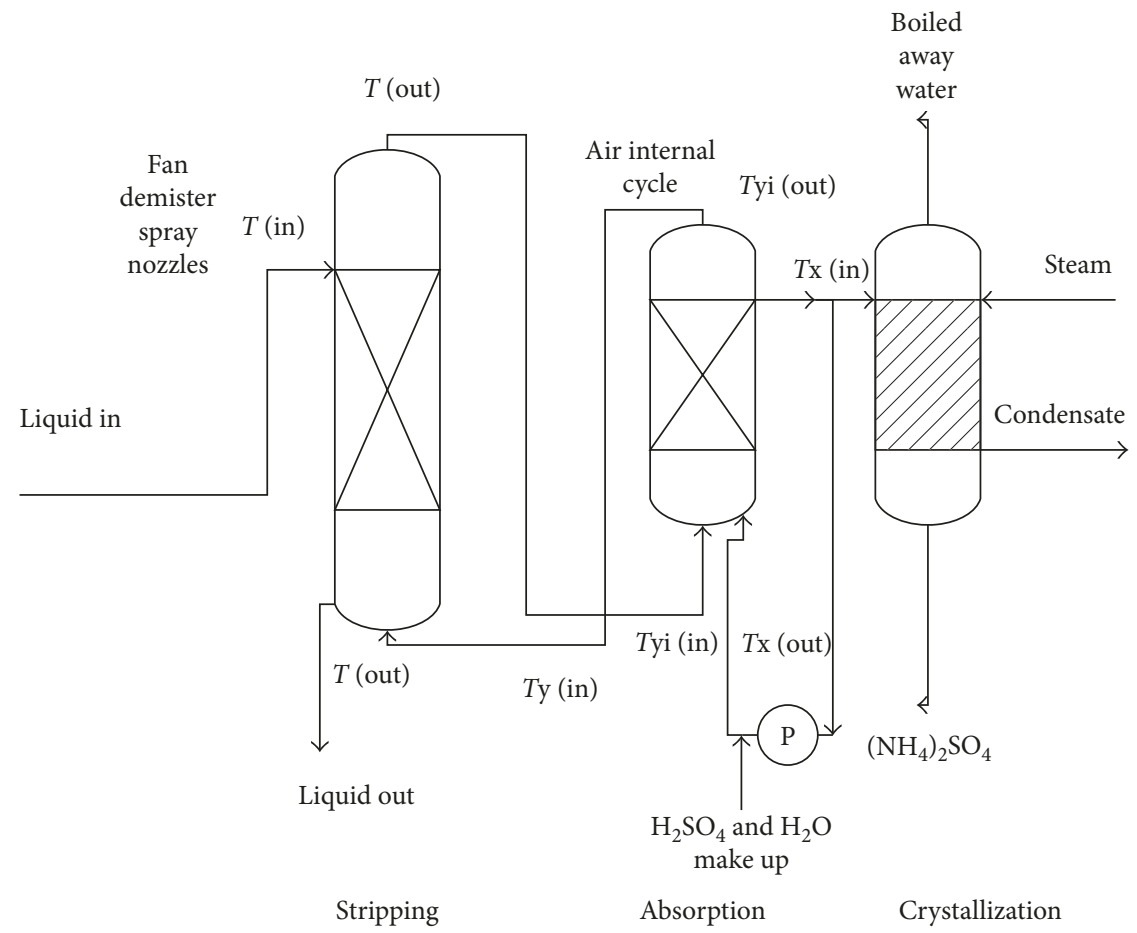

FIGURE 3: Proposed plant for ammonia stripping for industrial effluent application [12].

Nonetheless, Serna-Maza et al. revealed that in-situ ammonia stripping in mesophilic condition was unlikely to have any commercial application for wastes with intermediate total ammonia nitrogen concentrations as only high total ammonia nitrogen concentration stripping had managed to reduce the total ammonia nitrogen concentration below the higher inhibition threshold of approximately $8 \mathrm{~g} \cdot \mathrm{N} \cdot \mathrm{L}^{-1}[29]$. Thus, stripping coupled with dilution may offer the best means of controlling total ammoniacal nitrogen concentrations. Next, Collivignarelli et al. found that ammonia stripping without dosage of basificant had been feasible when the initial alkalinity of the leachate was equal to or greater than the acidity of ammonium ions for removal [30]. Notably, this can potentially minimize chemical usage and slash operational cost in removing ammonia nitrogen from leachate. Ammonia stripping also 
TABLE 1: Several studies that had looked into the ammonia stripping process with varied types of industrial wastewater.

\begin{tabular}{|c|c|c|c|c|c|}
\hline Wastewater & $\begin{array}{l}\text { Ammonia } \\
\text { stripping } \\
\text { reactor }\end{array}$ & $\begin{array}{l}\text { Influent ammonia } \\
\qquad(\mathrm{mg} / \mathrm{L})\end{array}$ & $\begin{array}{c}\text { Ammonia } \\
\text { removal } \\
\text { percentage }(\%) \\
\end{array}$ & Operating condition & Reference \\
\hline $\begin{array}{l}\text { Biologically treated blue } \\
\text { crab processing wastewater }\end{array}$ & Packed bed & 2300 & 72 & $\begin{array}{l}\text { Liquid loading rate: } \\
25 \mathrm{~L} / \mathrm{m}^{2} / \mathrm{min} \\
\text { Temperature: } 14^{\circ} \mathrm{C} \\
\text { PH: } 12.0\end{array}$ & {$[20]$} \\
\hline Petroleum refinery wastewater & Packed bed & 100 & 85 & $\begin{array}{l}\text { Airflow rate: } 8495.1 \mathrm{~L} \text { of } \\
\text { air/gal of wastewater } \\
\text { Temperature: } 25^{\circ} \mathrm{C} \\
\text { pH: } 10.5 \\
\text { Airflow rate: } 4500 \mathrm{~L} \cdot \mathrm{h}^{-1}\end{array}$ & {$[21]$} \\
\hline Landfill leachate & Packed bed & 1213 & 88 & $\begin{array}{c}\text { Temperature: } 25^{\circ} \mathrm{C} \\
\text { pH: } 11\end{array}$ & {$[22]$} \\
\hline Piggery wastewater & Packed bed & 4950 & 80 & $\begin{array}{c}\text { Airflow rate: } 10 \mathrm{~L} / \mathrm{min} \\
\text { Temperature: } 37^{\circ} \mathrm{C} \\
\text { pH: } 11 \\
\text { Airflow rate: } 420 \mathrm{~m}^{3} \cdot \mathrm{m}^{-2} \cdot \mathrm{h}^{-1}\end{array}$ & {$[23]$} \\
\hline Fertilizer effluent & Packed bed & 2000 & 99 & $\begin{array}{c}\text { Temperature: } 26^{\circ} \mathrm{C} \\
\text { pH: } 11\end{array}$ & {$[24]$} \\
\hline Raw manure digestate & Mixer & 5000 & 88.7 & $\begin{array}{c}\text { Temperature: } 23^{\circ} \mathrm{C} \\
\text { pH: } 10\end{array}$ & [19] \\
\hline Secondary effluent & Packed bed & 12 & 86.2 & $\begin{array}{c}\text { Airflow rate: } 100 \mathrm{~L} / \mathrm{min} / \mathrm{sq} \cdot \mathrm{m} \\
\text { Temperature: } 20.6^{\circ} \mathrm{C} \\
\text { pH: } 11.7\end{array}$ & {$[10]$} \\
\hline $\begin{array}{l}\text { Acetylene purification } \\
\text { wastewater }\end{array}$ & Packed bed & 125 & $91 \%$ & $\begin{array}{c}\text { Airflow rate: } 0.5 \mathrm{~m}^{3} / \mathrm{h} \\
\text { Temperature: } 60^{\circ} \mathrm{C} \\
\text { pH: } 12\end{array}$ & {$[25]$} \\
\hline $\begin{array}{l}\text { Ammonia-rich soda ash } \\
\text { wastewater }\end{array}$ & $\begin{array}{l}\text { Microwave- } \\
\text { assisted } \\
\text { air stripping }\end{array}$ & 1350 & $96.3 \%$ & $\begin{array}{l}\mathrm{pH}: 11 \text {; time: } 5 \text { mins } \\
\text { microwave radiation } \\
\text { power: } 750 \mathrm{~W}\end{array}$ & {$[26]$} \\
\hline $\begin{array}{l}\text { Sludge liquor from municipal } \\
\text { wastewater treatment plants }\end{array}$ & $\begin{array}{l}\text { Ion exchanger } \\
\text { loop stripping }\end{array}$ & 2300 & $84.6 \%$ & pH: 10.5 & {$[27]$} \\
\hline Swine wastewater & $\begin{array}{l}\text { Microwave- } \\
\text { assisted } \\
\text { air stripping }\end{array}$ & 2740 & 88.2 & $\begin{array}{c}\mathrm{pH}: 11 \\
\text { microwave } \\
\text { radiation: } 700 \mathrm{~W}\end{array}$ & {$[28]$} \\
\hline
\end{tabular}

appears to be effective and suitable in agriculture due to its simple process and cost-effectiveness in removing ammonia efficiently.

\section{Process Condition}

Numerous studies have highlighted the impacts of varying operational parameters upon the performance of ammonia stripping process. Some important parameters that have been reported to influence the performance of ammonia stripping are temperature, $\mathrm{pH}$, and air to water ratio.

4.1. Temperature. Temperature has been proven to have a significant impact on the performance of ammonia stripper. This is because the solubility of ammonia in water is governed by Henry's law. In Henry's law, the constant of gas relies on solute, solvent, and temperature [31]. For example, Campos et al. discovered that the removal of ammonia from landfill leachate at $60^{\circ} \mathrm{C}$ was relatively significant over a period of 7 hours than at $25^{\circ} \mathrm{C}$ [32]. Generally, higher efficiency ammonia removal can be obtained at higher temperature. Saracco and Genon also found that the capital cost of ammonia stripper at a stripping temperature of $80^{\circ} \mathrm{C}$ was less by half than that at $40^{\circ} \mathrm{C}$. Nevertheless, from the economic stance, increment in temperature may lead to a hike in the cost of preheating [12].

4.2. $p H$. Ammonia nitrogen in water exists in equilibrium between the molecular $\left(\mathrm{NH}_{3}\right)$ and ionic form $\left(\mathrm{NH}_{4}{ }^{+}\right)$ according to the following reaction:

$$
\mathrm{NH}_{3}+\mathrm{H}_{2} \mathrm{O} \longleftrightarrow \mathrm{NH}_{4}^{+}+\mathrm{OH}^{-}
$$

The distribution between molecular ammonia and ammonium ions in water can be defined by (2) [16] and (3) [18]:

$$
\begin{aligned}
{\left[\mathrm{NH}_{3}\right] } & =\frac{\left[\mathrm{NH}_{3}+\mathrm{NH}_{4}^{+}\right]}{1+\left[\mathrm{H}^{+}\right] / K_{\mathrm{a}}} \\
p K_{\mathrm{a}} & =4 \times 10^{-8} \mathrm{~T}^{3}+9 \times 10^{-5} \mathrm{~T}^{2}+0.0356 \mathrm{~T}+10.072,
\end{aligned}
$$

where $\left[\mathrm{NH}_{3}\right]$ is the molecular ammonia concentration, $\left[\mathrm{NH}_{3}+\mathrm{NH}_{4}^{+}\right]$is the total ammonia concentration, $\left[\mathrm{H}^{+}\right]$is the hydrogen ion concentration, and $K_{\mathrm{a}}$ is the acid ionization constant. Besides that, $p K_{\mathrm{a}}$ can be expressed in terms 
of temperature as shown in (3). Higher $\mathrm{pH}$ favors the formation of ammonia gas whereas lower $\mathrm{pH}$ favors the formation of ammonium ions. Hence, raising the $\mathrm{pH}$ level of the wastewater prior ammonia stripping is crucial to favor the formation of molecular ammonia nitrogen for stripping. However, according to Hidalgo et al., excessive rise of $\mathrm{pH}$ poses extra cost of lime that is nonfeasible in terms of cost. Hence, an optimum $\mathrm{pH}$ is required to strike a balance between process efficiency and economic cost. They found that when the $\mathrm{pH}$ exceeded 10.5, the removal efficiency was insignificant because $\mathrm{pH}$ no longer the affected the ionization balance between molecular ammonia and ionic ammonium but the cost incurred rose significantly due to the additional lime consumption required to increase the $\mathrm{pH}$ levels [33]. Meanwhile, Markou et al. revealed insignificant effect for the types of alkali (potassium hydroxide, sodium hydroxide, and calcium hydroxide) used on the ammonia removal efficiency [34]. However, calcium alkali was preferable due to reduction of solids, heavy metal concentrations, and color of wastewater [35].

4.3. Air to Water Ratio. Air to water ratio is an important parameter that has an impact on the removal rates of ammonia in water. Mass transfer of ammonia into the air is affected by the variance between ammonia concentration level in liquid form and air phase [18]. Lei et al. discovered that the ammonia stripping efficiency of anaerobic effluent was influenced by air/water ratios. The study found that higher ammonia removal rate was achieved after $12 \mathrm{~h}$ at an airflow rate of $10 \mathrm{~L} / \mathrm{min}$, in comparison to airflow rates at $3 \mathrm{~L} / \mathrm{min}$ and $5 \mathrm{~L} / \mathrm{min}$ [16]. Nevertheless, from the engineering stance, Lei et al. concluded that $5 \mathrm{~L} / \mathrm{min}$ for $1 \mathrm{~L}$ of anaerobic effluent should be feasible due to the expensive method of using an airflow rate of $10 \mathrm{~L} / \mathrm{min}$ for $1 \mathrm{~L}$ of wastewater with only $5 \%$ increment in removal efficiencies, as compared to airflow rates from $5 \mathrm{~L} / \mathrm{min}$ until $10 \mathrm{~L} / \mathrm{min}$ [16]. Next, Campos et al. revealed that the influence of air to water ratio on ammonia stripping performance at higher temperature was less significant as it resulted in ammonia removal greater than $91 \%$ at $60^{\circ} \mathrm{C}$ with an airflow rate between $73 \mathrm{~L} / \mathrm{h}$ and $120 \mathrm{~L} / \mathrm{h}[32]$.

\section{Issues Related to Ammonia Stripper Wastewater in Industrial Treatment Application}

The ammonia stripping process has been successfully employed for many types of high-strength ammonia wastewater (Table 1). The method refers to one that is controlled and unaltered by toxic compounds. Nevertheless, the ammonia stripping process has several drawbacks. Among the issues involving the implementation of ammonia stripper to remove ammonia nitrogen in wastewater are fouling problems, sludge production, and release of ammonia gas.

5.1. Fouling Problems. The fouling problems in an ammonia stripper tower are caused by the formation of calcium carbonate scale on the surface of the packing materials. Scale builds up on the packing materials, thus leading to lower stripping performance [32]. Viotti and Gavasci found that the progressive scaling of the packing reduced stripper efficiency from $98 \%$ to $80 \%$ after 6 months of operation. The formation of calcium carbonate scale on the packing material is due to the absorption of carbon dioxide from the air stream used for stripping. Moreover, the nature of calcium carbonate varies from soft to hard. Viotti and Gavasci, thus, suggested chemical cleaning to attain higher removal of ammonia from wastewater [36]. The high operation and maintenance cost for air stripping can be attributed to the formation of calcium carbonate scale [37].

5.2. Sludge Production. The stripped effluent of ammonia stripping often fails in meeting the discharge standards. High sludge production and high alkalinity effluent associated with ammonia stripping generate additional treatment cost to this process. However, the calcium carbonate from the ammonia stripper sludge can be recovered. Maree and Zvinowanda, for example, used the flotation technique to recover calcium carbonate from wastewater treatment sludge [38]. As a result, they discovered that floatation technique can potentially recover commercial grade limestone from wastewater sludge [38]. Meanwhile, He et al. assessed the feasibility and performance enhancement for treatment of alkaline-stripped effluent in aerated constructed wetlands [39]. The constructed wetland was relatively simple and was empowered with eco-friendly technology so that it can withstand extreme $\mathrm{pH}$ wastewater. $\mathrm{He}$ et al. also found that the remediation of alkaline effluent was feasible due to the high buffering capacity of the wetlands [39].

5.3. Ammonia Gas. The ammonia stripping process results in ammonia release into the environment, thus causing additional environmental issues. Ammonia recovery by absorption is generally employed to prevent ammonia gas from being directly released into the environment. Ferraz et al. used sulphuric acid to recover the stripped ammonia from landfill leachate and revealed that $87 \%$ of the stripped ammonia was recovered [22]. Next, Zhu et al. discovered that under optimal condition of $\mathrm{pH} \mathrm{12,} \mathrm{airflow} \mathrm{rate} \mathrm{of}$ $0.50 \mathrm{~m}^{3} / \mathrm{h}$, temperature of $60^{\circ} \mathrm{C}$, and stripping time of $120 \mathrm{~min} ; 0.2 \mathrm{~mol} / \mathrm{L}$ of sulphuric acid can absorb approximately $93 \%$ of the ammonia stripped per volume of the acetylene purification wastewater [25]. Meanwhile, Laureni et al. concluded that ammonia stripping coupled with absorption proved to be a feasible option for valorization of nitrogen found in pig slurry. The by-product of this process was ammonium sulphate, which is a marketable product in the agriculture arena as fertilizers [15].

\section{Advances in Ammonia Stripping Process}

Research on ammonia stripping enhancement has continued unabated. Recent development of ammonia removal by ammonia stripping fall into the following: ammonia stripping reactor modifications, membrane contactor, membrane 


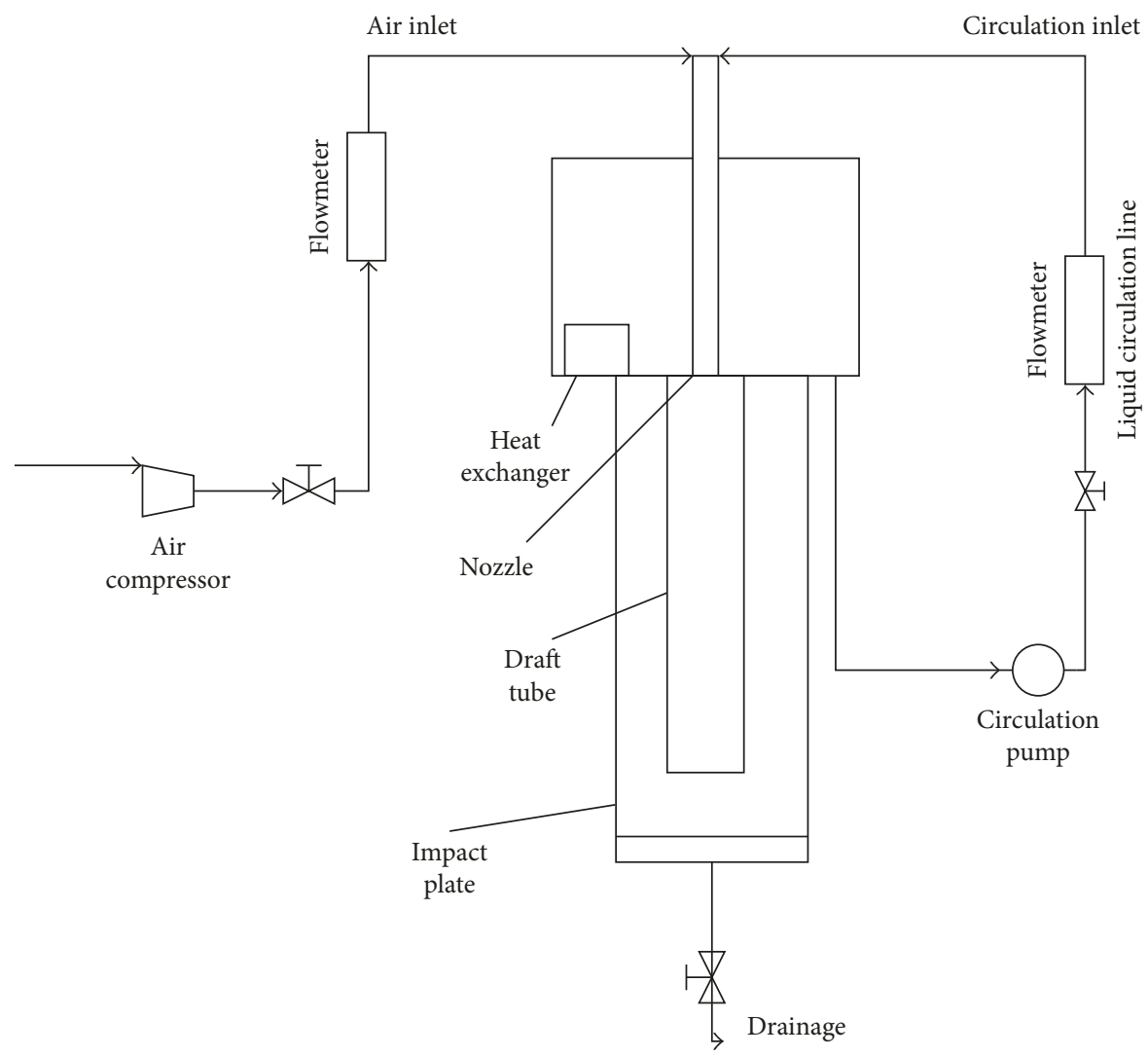

Figure 4: Schematic diagram of jet loop reactor [42].

distillation, ion exchange-stripping loop, and microwaveassisted ammonia stripping.

6.1. Ammonia Stripping Reactor Modifications. The construction of a particular ammonia stripping reactor is crucial as it has a strong impact on the whole treatment efficiency and the capital cost. The conventional ammonia stripper reactor employs the packed column technology, in which the packing materials are used to enhance mass transfer between the two phases. The countercurrent-packed tower draws air through its openings at the bottom as the wastewater is pumped to the top of the packed tower. Nonetheless, this process generates carbonate scales on the surface of the packing materials, which can affect ammonia removal efficiencies over time. Apart from that, the average depth of the packed bed tower can range from 6.1 until 7.6 meters, hence consuming a considerably large amount of space. Therefore, some researchers have suggested the use of innovative ammonia stripper reactors as a solution for efficient removal of ammonia. Among the innovative ammonia stripping reactors proposed were rotating packed bed [40], water-sparged aerocyclone reactor [41], and semibatch jet loop reactor [42].

6.1.1. Semibatch Jet Loop Reactor. Removal of ammonia via air stripping in a semibatch jet loop reactor was initiated by Degermenci et al., in which ammonia is removed by a jet loop reactor so as to reduce the construction and operational costs of the conventional ammonia stripping process. It also has a higher mass transfer coefficient and easier adaption from the pilot scale to the industrial-scale [42]. The jet loop reactor was conventionally applied for chemical or biochemical catalyzed reactions [43]. The jet loop reactor offers exceptional mixing performance at relatively low energy consumption for application that involves mass transfer [44].

An overall overview of the jet loop reactor is illustrated in Figure 4. In general, the jet loop reactors were constructed in many designs in terms of apparatus, nozzle dimensions, draft tube, and entry position of the jet stream [45]. The principle of the jet loop reactor is the utilization of the kinetic energy of high-velocity liquid jet to entrain the gas phase, besides producing fine dispersion between the gas and the liquid phases [46].

Degermenci et al. have developed (4) to model the rate of ammonia removal via air-stripping technique in a jet loop reactor [42].

$$
-\ln \frac{C_{\mathrm{L}, t}}{C_{\mathrm{L}, 0}}=\frac{K_{\mathrm{H}} Q_{\mathrm{G}}}{V_{\mathrm{L}}}\left[1-e^{-\left(\left(K_{\mathrm{L}} a S L e\right) /\left(\mathrm{Q}_{\mathrm{G}} K_{\mathrm{H}}\right)\right)}\right] t .
$$

As a result, the temperature and the gas flow rate exhibited significant impacts on the ammonia removal rate by using the jet loop reactor. Besides, the jet loop appeared to be more effective than the conventional ammonia stripper packed tower. The jet loop reactors can also be used for the conversion processes in treating biochemical wastewater. Farizoglu et al. studied the treatment of cheese whey in a jet loop membrane reactor and achieved $84-94 \%$ of chemical 


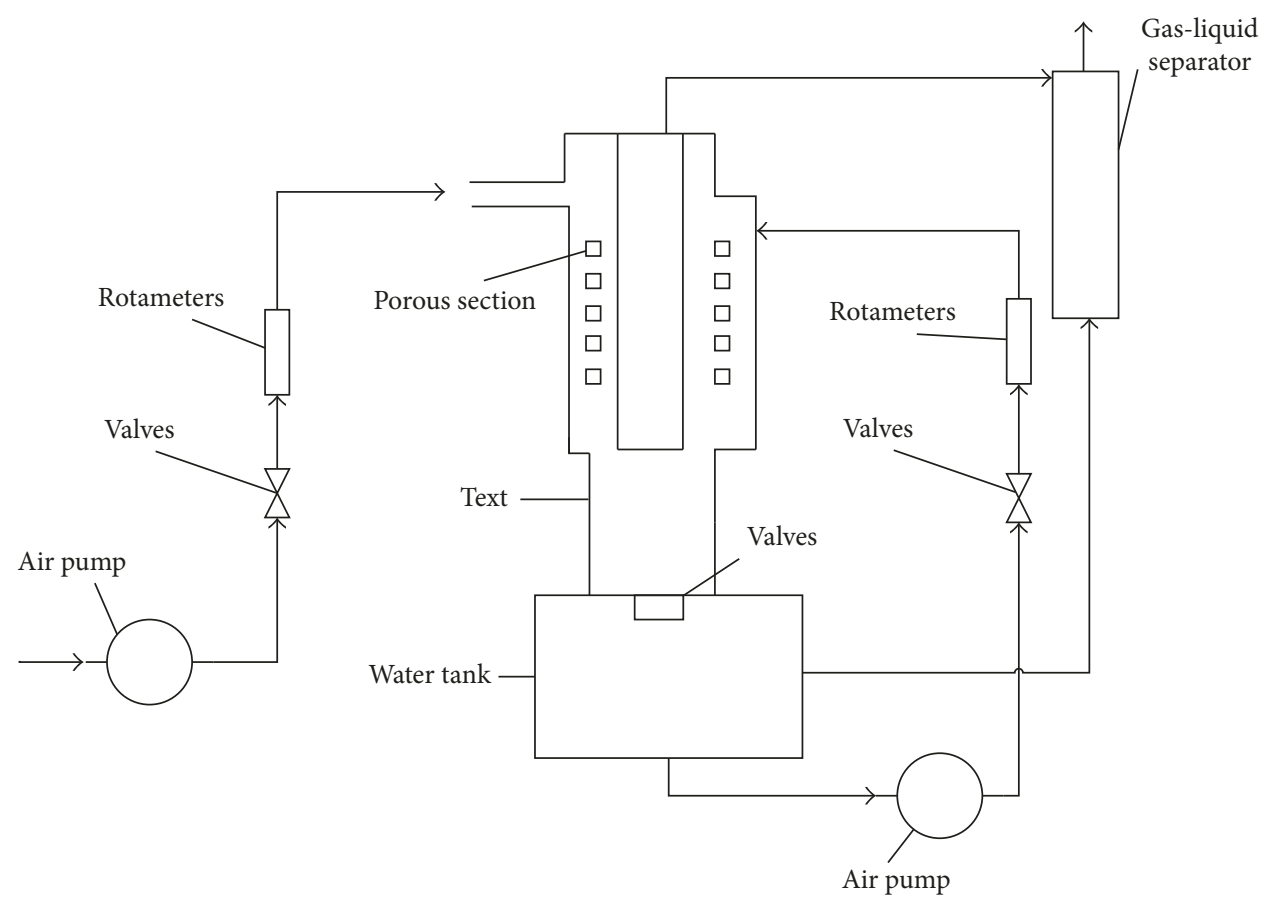

FIGURE 5: Water-sparged aerocyclone reactor configurations.

oxygen demand removal, which possessed the capability to operate at high biomass concentrations [47]. Next, Eusebio et al. investigated the treatment of winery wastewater by using jet loop reactor and found that $80 \%$ of COD removal efficiencies had been achieved within 24 hours [48].

6.1.2. Water-Sparged Aerocyclone Reactor. Removal of ammonia via water-sparged aerocyclone reactor was first designed by Quan et al. The basic motivation for the innovation was to increase the mass transfer rate and its applicability to treat wastewater with suspended solids [41]. The water-sparged aerocyclone gas-liquid contactor can be used to address two major drawbacks of the conventional packed tower, which are the process performance and the fouling problems in long operations.

The water-sparged aerocyclone reactor is illustrated schematically in Figure 5. The water-sparged reactor is comprised of two concentric right-vertical tubes and a cyclone header on the upper section. Wastewater is pumped into the porous section of the inner tube and sprayed into the centerline of the watersparged aerocyclone reactor. After that, air is drawn into the aerocyclone at the top header of the inner tube.

Quan et al. adopted (5) developed by Matter-Muller et al. to model the ammonia removal rate via air-stripping technique using the water-sparged aerocyclone [49].

$$
-\ln \frac{C_{\mathrm{A}, t}}{C_{\mathrm{A}, 0}}=\frac{H_{\mathrm{A}} Q_{\mathrm{G}}}{V_{\mathrm{L}}}\left[1-e^{-\left(\left(K_{\mathrm{L}} a V_{\mathrm{L}}\right) /\left(\mathrm{Q}_{\mathrm{G}} H_{\mathrm{A}}\right)\right)}\right] t .
$$

It was found that the water-sparged aerocyclone removed ammoniacal nitrogen, total phosphorus, and COD from wastewater at $91.0 \%, 99.2 \%$, and $52.0 \%$, respectively. Due to the promising ammonia removal efficiency by the water-sparged aerocyclone reactor, the structure of the water-sparged aerocylone reactor was improvised by Quan et al. to maximize the mass transfer efficiency of the reactor [50]. Quan et al. also investigated the arrangement and the diameter of the jet holes in water-sparged aerocyclone reactor, thus concluding that the spray holes should be arranged in a square mode with $1.28 l_{c}$ of optimum distance between two adjacent spray holes [50].

6.1.3. Rotating Packed Bed Reactors. Ammonia removal via air-stripping technique in the rotating packed bed reactor was conducted by Yuan et al. to enhance the high volumetric gas-liquid mass transfer coefficients, as well as to reduce the fouling problem, the equipment size, and the cost incurred, as an attempt to overcome the shortcomings detected in the conventional ammonia stripping technique. The rotating packed bed reactor appeared to be highly efficient in process intensification as it maximized the gas-liquid mass transfer efficiency via strong centrifugal acceleration [51].

In fact, this particular method have been employed in a number of industrial applications, namely, absorption [52], synthesis of biodiesel [53], hydrogen sulfide removal [54], and synthesis of nanoparticles [55].

The rotating packed bed is illustrated schematically in Figure 6 . The rotating packed bed consists of a rotating packed bed, gas and influent controls, effluent analyzer, and effluent gas neutralizer [40].

Yuan et al. used (6) to model the ammonia removal rate via air stripping using the rotating packed bed reactor [40]:

$$
K_{\mathrm{L}} a=\frac{Q_{\mathrm{L}}}{V_{\mathrm{B}}} \frac{\ln \left[(1-(1 / S))\left(C_{L, \text { in }} / C_{L, \text { out }}\right)+(1 / S)\right]}{1-(1 / s)} .
$$




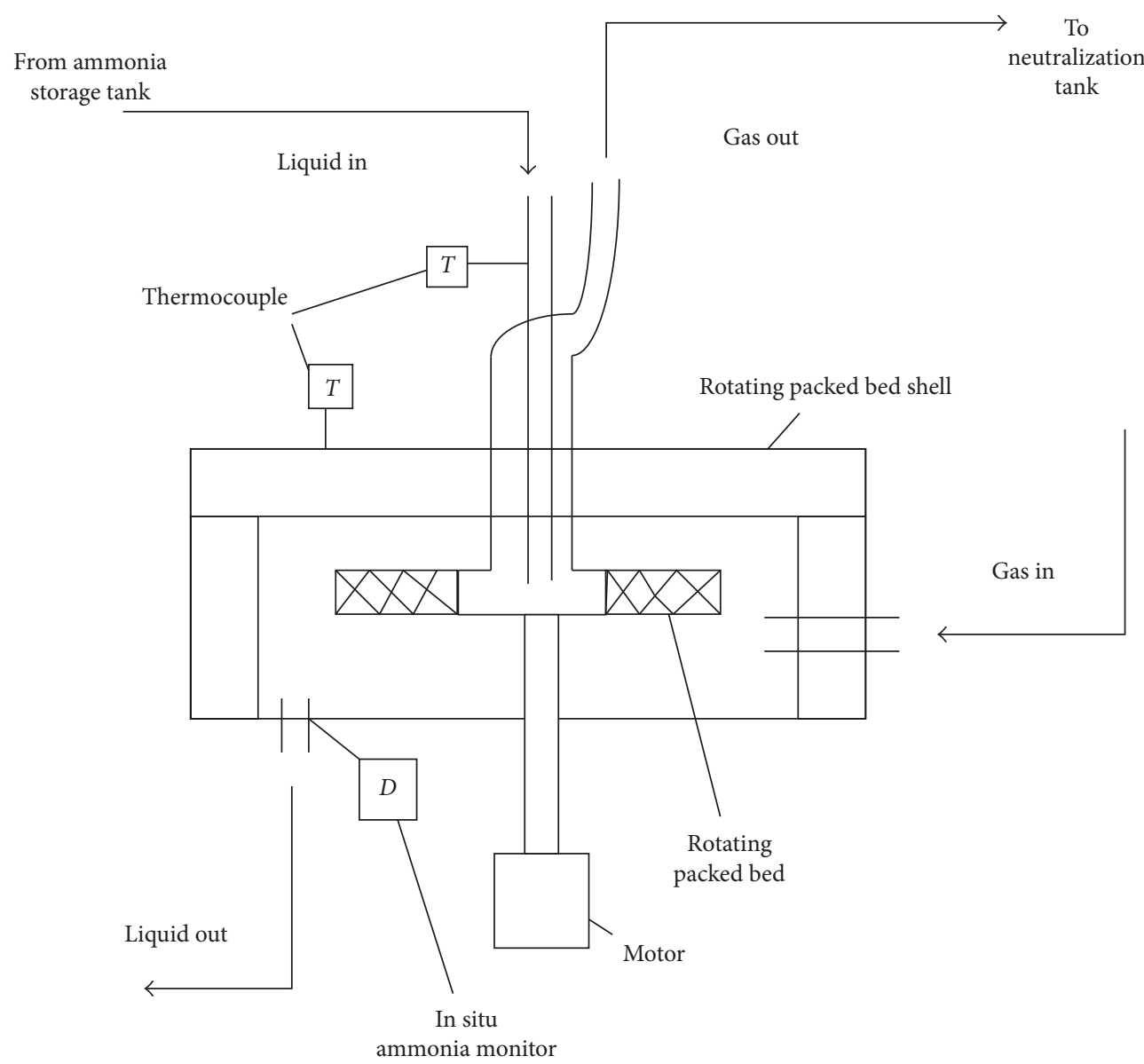

FIGURE 6: Rotating packed bed reactor configuration for ammonia stripping.

It was found that the rotating packed bed displayed higher mass transfer efficiency $(12.3-18.41 / \mathrm{h})$, when compared to other conventional and advanced gas-liquid contactors. Nonetheless, information concerning economic feasibility of the operating conditions seemed scarce for packed bed reactors in industrial wastewater treatment [40].

6.2. Membrane Contactors. Ammonia stripping by using membrane contactor is another alternative that has lower tendency to fouling and requires no post effluent treatment [56]. Relatively, ammonia stripping by membrane contactor has a higher rate of mass transfer than the conventional ammonia stripping due to its large contact surface area between the wastewater and stripping solution [57]. Semmens et al. have derived (7) to model the ammonia removal rate by ammonia stripping by using membrane contactor [56]:

$$
\ln \frac{C_{\mathrm{o}}}{C}=\frac{Q_{\mathrm{t}}}{V}\left(1-e^{(-k a L / v)}\right) \text {. }
$$

Ahn et al. have founded that the highest mass transfer coefficient by using PTFE membrane was at $11 \times 10^{-3} \mathrm{~m} / \mathrm{h}$ at the operating condition of $1000 \mathrm{mg} / \mathrm{L}$ of ammonia initial concentration with no suspended solids and temperature difference [57]. Hasanoglu et al. investigated the ammonia removal by using flat sheet and hollow fiber membrane contactors and founded that the circulation configuration solution has a strong impact on the efficiency of the process [58]. Tan et al. studied the ammonia removal by using polyvinylidene fluoride (PVDF) hollow membranes and founded that mass transfer rate is higher at higher feed velocity, but only up to $0.59 \mathrm{~m} / \mathrm{s}$ [59]. The ammonia stripping by using membrane contactor is illustrated schematically in Figure 7.

6.3. Membrane Distillation. In recent years, there has been an increasing research on ammonia removal using membrane distillation. Membrane distillation is driven by the temperature difference across the permeable membrane. It offers prospective recycling and reuse of industrial wastewater and higher process efficiency. Membrane distillation can be grouped into four basic configurations, namely, direct contact membrane distillation [60], vacuum membrane distillation [61], air gap membrane distillation [62], and sweep gas membrane distillation [63]. Liu et al. reported that direct contact membrane distillation process ammonia removal rate was more than $85 \%$ at ammonia concentration higher than $400 \mathrm{mg} / \mathrm{L}$, but the removal rate decreased as the ammonia concentration was above $1200 \mathrm{mg} / \mathrm{L}$ [60]. ElBourawi et al. addressed that the most important operating parameters that affect the ammonia removal efficiency of 


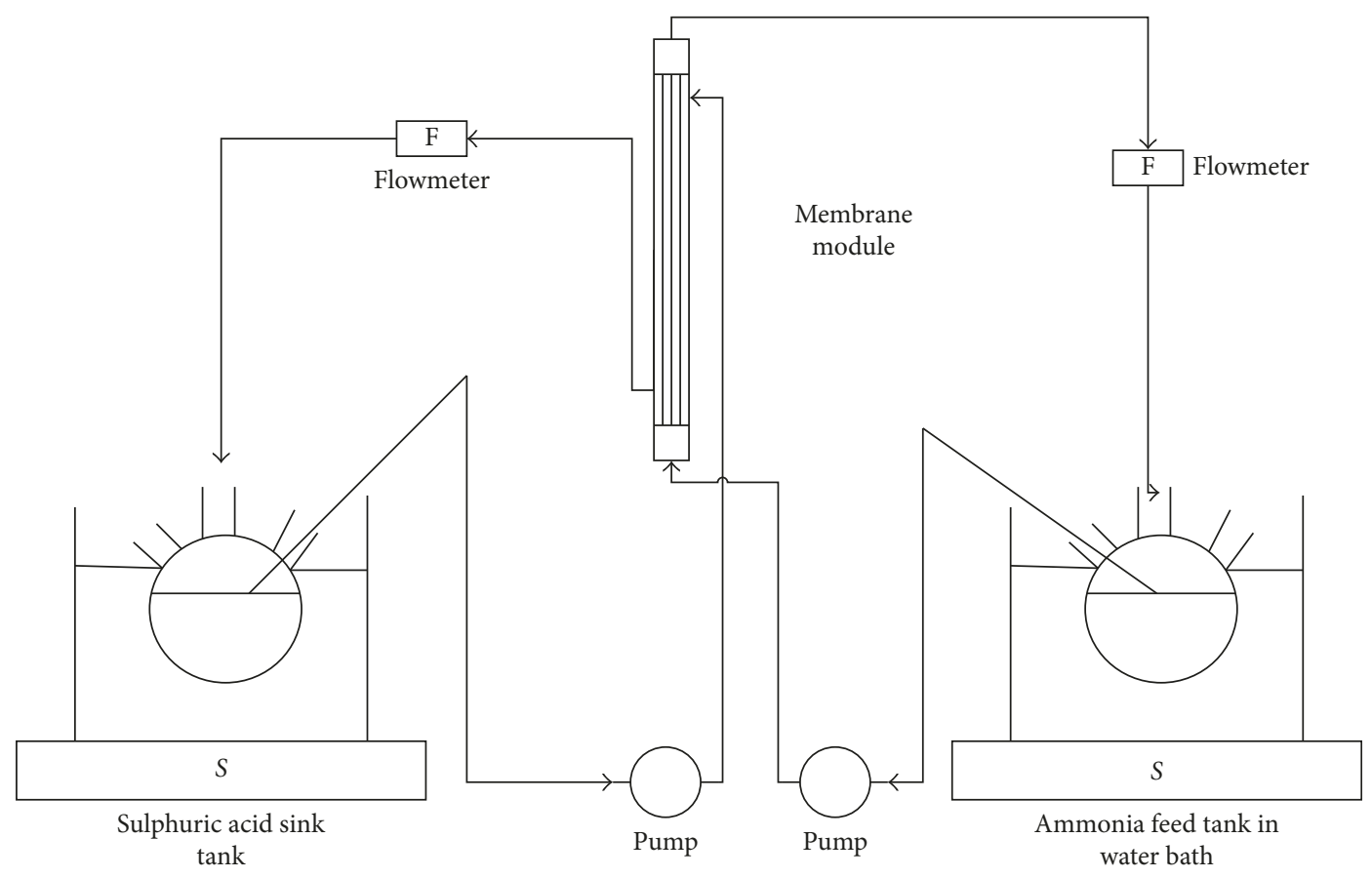

Figure 7: Membrane contactor configuration for ammonia stripping [59].

the vacuum membrane distillation are feed temperature, feed flow velocity, and downstream pressure. They reported that ammonia removal efficiencies higher than $90 \%$ were achieved by using vacuum distillation [61]. Eykens et al. conducted a lab scale and pilot scale on ammonia stripping by direct contact and air gap membrane distillation. It was founded that air gap membrane distillation has better performance and lower energy requirement than direct contact membrane distillation for larger scale applications [62]. Xie et al. investigated the ammonia removal by sweep gas membrane distillation. The efficiency of the process was affected by the feed temperature, feed flow rate, and gas flow rate. It was founded that sweep gas membrane distillation showed promising result with regards to high-efficiency industrial process water recycling [63]. The removal efficiency of the sweep gas membrane distillation was reported to be up to $97 \%$. Liu et al. reported that the asymmetric PVDF membrane possesses excellent antifouling and sustainable flux in relative with the commercial PTFE (polytetrafluoroethylene) membrane [64]. It was founded that the PVDF membrane has less than $8 \%$ flux decline in 15 hours continuous operation [64].

6.4. Ion Exchange Loop Stripping. Due to the problems associated with operating and maintenance costs of air stripping [65] and the economic viability of the resins used for ion exchange [66], ion exchange and air stripping are combined and called ion exchange loop-stripping. The ion exchange loop stripping offers relatively lower operating and investment cost due to the reduced energy demands and equipment size reductions [67]. The ion exchange loop stripping is illustrated schematically in Figure 8. Ion exchange loop stripping is made up of the zeolite bed, stripping column, and a scrubber.

Ellersdorfer suggested that sodium hydroxide solution may be an alternative to sodium chloride to reduce chemical consumption [27]. Ellersdorfer has investigated the technical feasibility of ammonium recovery by using ion exchange loop stripping for sludge liquor from municipal wastewater treatment plants and founded that it can be a feasible option for recovering ammonium from sludge liquor wastewater treatment plants at above $900 \mathrm{mg} / \mathrm{L}$ [27].

6.5. Microwave-Assisted Air Stripping. Reports on microwave radiation that could be used to reduce ammonia nitrogen in wastewater have opened the door for research in the field of ammonia stripping by microwave radiation. Li Lin et al. implemented a pilot-scale study of ammonia removal by using microwave radiation and founded that $80 \%$ ammonia removal from coke-plant wastewater can be achieved [26]. Ata et al. carried out studies on optimization of ammonia removal microwave-assisted air stripping and founded that the optimum conditions were at $1800 \mathrm{mg} / \mathrm{L}$ of initial concentrations, $7.5 \mathrm{~L} \cdot \mathrm{min}^{-1}$ of airflow rate, $60^{\circ} \mathrm{C}$ of temperature, $500 \mathrm{rpm}$ of stirring speed, and $200 \mathrm{~W}$ microwave output with 60 minutes of radiation. The removal efficiency of microwaveassisted ammonia stripping was able to achieve $94.2 \%$ under optimized conditions [68]. La et al. evaluated the efficiencies of microwave-assisted ammonia removal from swine wastewater. The highest removal efficiency was obtained at $83.1 \%$. Ammonia removal by microwave radiation offers high ammonia removal rate and lower reaction time [28]. However, more research is needed for optimizing the power consumption of this wastewater treatment system. 


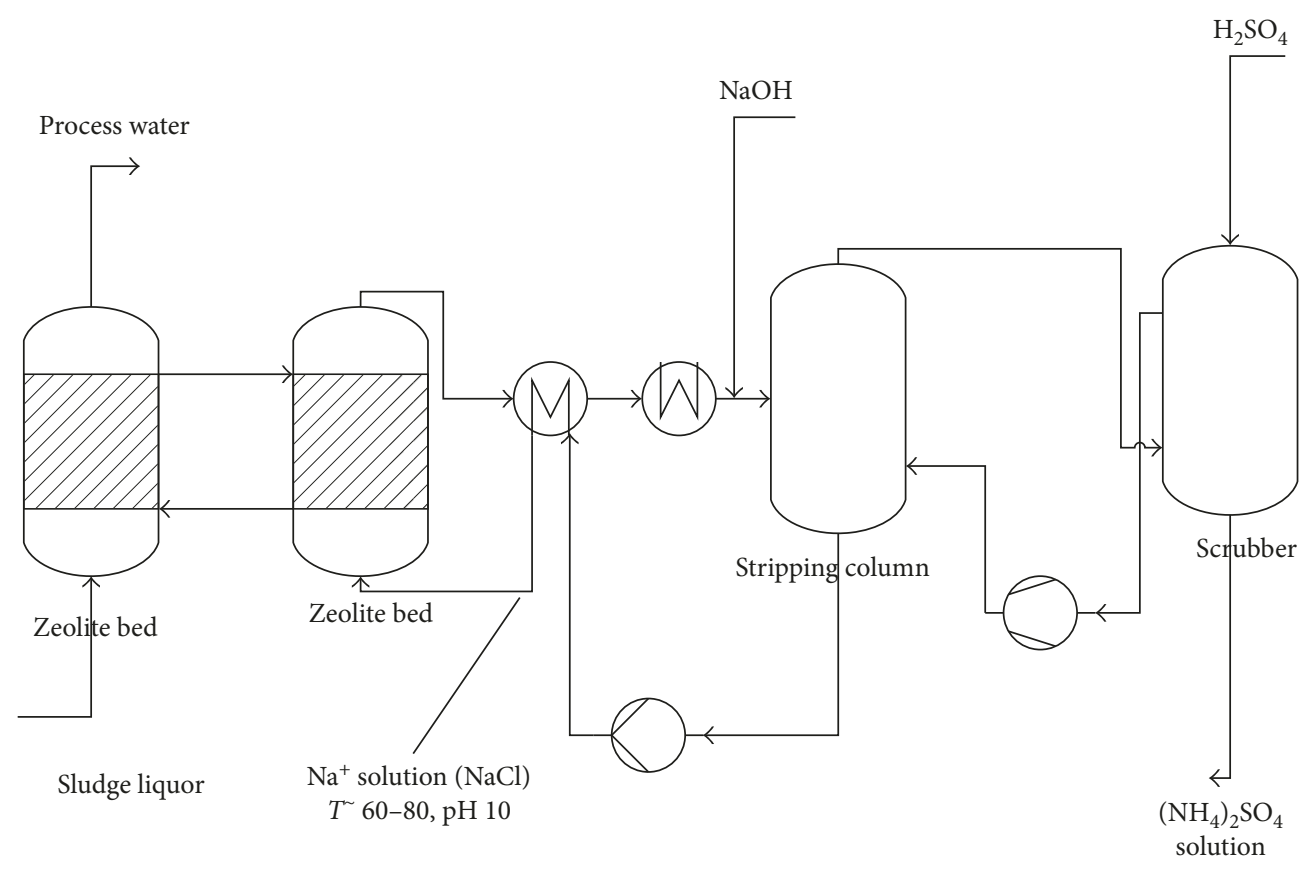

Figure 8: Ion exchange loop stripping configurations [27].

\section{Comparisons between Different Ammonia Stripping Processes}

A comparison of various parameters related to the different ammonia stripping processes based on literature was tabulated in Table 2.

Table 2 shows that among the processes evaluated, the packed tower displayed a higher tendency towards fouling, which decreased its efficiency and increased the operational cost of the whole process. Besides, the packed tower also required higher air consumption, when compared to the other ammonia stripper processes. Besides that, the packed tower also requires higher air consumption in relation with other ammonia stripper processes. However, the newer ammonia stripping processes such as, the semibatch jet loop reactor, water-sparged aerocyclone reactor, and rotating packed bed reactor, have lower tendency towards fouling problems. Since the rotating packed bed reactor operates in continuous flow, Yuan et al. suggested that larger rotating packed bed reactor has to be used to ensure higher process efficiency [40]. The water-sparged aerocyclone also offered simultaneous removal of other contaminants, such as total phosphorus and COD. In addition, the conventional packed tower displayed lower tolerance to total suspended solids. Hence, this technique is limited to applications with lower suspended solids present in wastewater. In this case, the ammonia stripping processes via semibatch jet loop reactor, water-sparged aerocyclone reactor, and rotating packed bed reactor are deemed suitable for wastewater that contains higher total suspended solids. It can also be seen that the implementation membrane technologies in ammonia stripping process have been receiving considerable attention in recent years. Separation technologies using membrane incorporated into the ammonia stripping has higher process efficiency and offers prospective wastewater reclamation and reuse [72]. However, the membrane technologies are subjected to membrane fouling which results in a substantial increase in hydraulic resistance [73]. Hence, future research should emphasize on the membrane fouling control and the performance on a larger scale. The microwave-assisted ammonia stripping also showed higher process efficiency at $94.2 \%$. Nonetheless, higher power consumption and running costs posed a serious challenge for the microwaveassisted ammonia stripping process [69].

\section{Summary of Review and Future Research Perspectives}

This review paper has revealed the inherent benefits of the ammonia stripping process, in comparison to the conventional packed tower. Nevertheless, pilot-scale investigation and economic evaluations are required before applying full scale of the ammonia stripping process. Moreover, future researches can specifically focus on the following three aspects.

First, the structure optimization for the each of the ammonia stripping process reactors deserves further research. Since most of the new advanced ammonia stripping reactors were first designed for various types of applications, it is important that these reactors are tailor-made for ammonia stripping processes. One of the most important aspects of ammonia stripping reactor's development refers to the higher air-stripping efficiency at a lower operational cost. Hence, structure optimization can illustrate a detailed design guide for optimized gas-liquid contactors.

Second, more studies are needed to evaluate the capital and operational costs for advanced liquid-gas contactors in ammonia stripping. Since studies regarding these important 


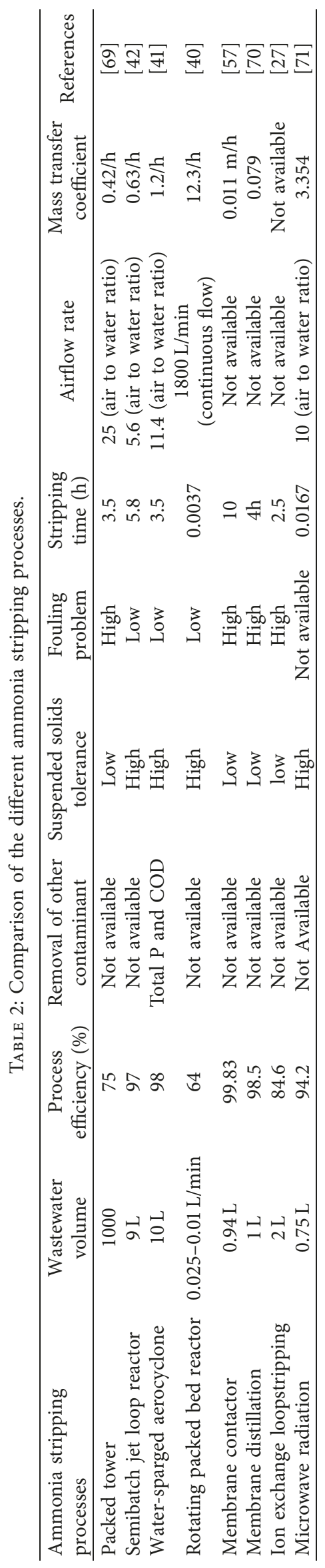


aspects are in scarcity, and such information is vital to engineers and decision-makers in-charge of devising new technologies, more evaluations are required to look into the full cost analysis of the advanced gas-liquid contactors so as to determine its economic feasibility for specific wastewater treatment scenario. Additionally, a detailed pilot study on the advanced gas-liquid contactors is also crucial to identify potential hiccups and allay investor concerns.

Third, two of the advanced gas-liquid contactors (rotating packed bed and water-sparged aerocyclone) utilize vortex to induce gas-liquid mass transfer. Hence, there is a possibility of harvesting energy from these water vortexes. As such, it has been proposed that the advanced gas-liquid contactors have to be integrated with water vortex generator. This may be a possible strategy to promote energy selfsufficient ammonia stripping process. Nishi and Inagaki investigated the vortex-type water turbine to generate electricity and discovered its ability in generating electricity by using a low head and a low flow rate using a simple structure [74]. This ammonia stripping reactor liquid, coupled with water vortex generator, seems to be a promising technology for energy self-sufficient wastewater treatment and demands further research.

\section{Conclusion}

Ammonia stripping process is suitable for treating wastewater that contains high concentration of ammonia and toxic compounds with the merits of simpler operation, high efficiency, and excellent treatment stability, thus displaying an exceptional application potential for industrial wastewater treatment. The success of an ammonia stripping process is greatly dependent on temperature, $\mathrm{pH}$, and air to water ratio. As such, the selection of optimized operating parameter is vital for the ammonia stripper to achieve higher efficiency. The different types of ammonia stripping reactors for ammonia stripping are presented in this review article. Its outstanding mass transfer performance and higher total suspended solids tolerance discriminate the conventional packed tower for ammonia stripping method. The following directions are proposed for further research. First, the structure optimization should be done for each of the ammonia stripping processes for higher air-stripping efficiency at a lower operational cost. Secondly, full cost analysis of the advanced ammonia stripper processes is needed to evaluate its economic feasibility for specific wastewater treatment scenario. Lastly, the integration of advanced gasliquid contactors with vortex power generator for an energy self-sufficient wastewater treatment is proposed.

\section{Conflicts of Interest}

The authors declare that they have no conflicts of interest regarding the publication of this paper.

\section{References}

[1] S. R. M. Kutty, S. N. I. Ngatenah, M. H. Isa, and A. Malakahmad, "Nutrients removal from municipal wastewater treatment plant effluent using Eichhornia crassipes," Engineering and Technology, vol. 3, no. 12, pp. 826-831, 2009.

[2] V. D. Leite, S. Prasad, W. S. Lopes, J. T. Sousa, and A. J. M. Barros, "Study on ammonia stripping process of leachate from the packed tower," Journal of Urban and Environmental, vol. 7, no. 2, pp. 21-222, 2013.

[3] T. A. Pressley, D. F. Bishop, A. P. Pinto, and A. F. Cassel, "Ammonia-nitrogen removal by breakpoint chlorination," 1973, https://nepis.epa.gov/Exe/ZyPDF.cgi/91020N8G.PDF? Dockey=91020N8G.PDF.

[4] Batelle-Northwest Richland, "Wastewater ammonia removal by ion exchange," 1971, https://nepis.epa.gov/Exe/tiff2png.cgi/ 9100GI2R.PNG?-r+75+g+7+D\%3A\%5CZYFILES\%5CINDEX\% 20DATA\%5C70THRU75\%5CTIFF\%5C00001708\%5C9100GI2R. TIF.

[5] M. Mondor, L. Masse, D. Ippersiel, F. Lamarche, and D. I. Masse, "Use of electrodialysis and reverse osmosis for the recovery and concentration of ammonia from swine manure," Bioresource Technology, vol. 99, no. 15, pp. 7363-7368, 2008.

[6] R. G. Rice, C. M. Robson, G. W. G. Miller, J. C. Clark, and W. Kohn, "Biological processes in the treatment of municipal water supplies," 1982, https://nepis.epa.gov/Exe/ZyPDF.cgi/ 9100LYD1.PDF?Dockey=9100LYD1.PDF.

[7] I. Ozturk, M. Altinbas, I. Koyuncu, and Y. C. Gomec, "Advanced physico-chemical treatment experiences on young municipal landfill leachates," Waste Management, vol. 23, no. 5, pp. 441-446, 2003.

[8] USEPA, "Wastewater technology fact sheet: ammonia stripping," 2000, https://nepis.epa.gov/Exe/ZyPDF.cgi/P10099PH. PDF? Dockey=P10099PH.PDF.

[9] L. K. Wang, Y.-T. Hung, and N. K. Shammas, Advanced Physicochemical Treatment Processes: Handbook of Environmental Engineering, Vol. 4, The Humana Press Inc., Totowa, NJ, USA, 2006.

[10] T. P. O’Farell, F. P. Frauson, A. F. Cassel, and D. F. Bishop, "Nitrogen removal by ammonia stripping," Journal of Water Pollution Control Federation, vol. 44, no. 8, pp. 1527-1535, 1972.

[11] M. Raboni, V. Torretta, O. Viotti, and G. Urbini, "Experimental plant for the chemico-physical treatment of groundwater polluted by MSW leachate, with ammonia recovery," Revista Ambiente \& Agua, vol. 8, no. 3, pp. 22-32, 2013.

[12] G. Sarraco and G. Genon, "High temperature ammonia stripping and recovery from process liquid wastes," Journal of Hazardous Materials, vol. 37, no. 1, pp. 191-206, 1994.

[13] A. Alitalo, A. Kyro, and E. Aura, "Ammonia stripping of biologically treated liquid manure," Journal of Environmental Quality, vol. 41, no. 1, pp. 273-20, 2012.

[14] K. C. Cheung, L. M. Chu, and M. H. Wong, "Ammonia stripping as pretreatment for landfill leachate," Water, Air, and Soil Pollution, vol. 94, no. 1-2, pp. 209-221, 1995.

[15] M. Laureni, J. Palatsi, M. Llovera, and A. Bonmati, "Influence of pig slurry characteristics on ammonia stripping efficiencies and quality of the recovered ammonium-sulfate solution," Journal of Chemical Technology and Biotechnology, vol. 88, no. 9, pp. 1654-1662, 2013.

[16] X. H. Lei, N Sugiura, C. P. Feng, and T. Maekawa, "Pretreatment of anaerobic digestion effluent with ammonia stripping and biogas purification," Journal of Hazardous Materials, vol. 145, no. 3, pp. 391-397, 2007.

[17] M. A. Rubia, M. Walker, S. Heaven, C. J. Banks, and R. Borja, "Preliminary trials of in situ ammonia stripping from source segregated domestic food waste digestate using biogas: effect 
of temperature and flow rate," Bioresource Technology, vol. 101, no. 24, pp. 9486-9492, 2010.

[18] A. Bonmati and X. Flotats, "Air stripping of ammonia from pig slurry: characterisation and feasibility as pre- or posttreatment to mesophilic anaerobic digestion," Waste Management, vol. 23, no. 3, pp. 261-272, 2003.

[19] A. Limoli, M. Langone, and G. Andreottola, "Ammonia removal from raw manure digestate by means of a turbulent mixing stripping process," Journal of Environmental Management, vol. 176, pp. 1-10, 2016.

[20] G. D. Boardman and P. J. McVeigh, "Use of air stripping technology to remove ammonia from biologically treated blue crab processing wastewater," Journal of Aquatic Food Product Technology, vol. 7, no. 4, pp. 81-97, 1998.

[21] B. V. Prather, "Wastewater aeration may be key to more efficient removal of impurities," Oil and Gas Journal, vol. 57, pp. 78-89, 1959.

[22] F. M. Ferraz, J. Povinelli, and E. M. Veira, “Ammonia removal from landfill leachate by air stripping and absorption," Environmental Technology, vol. 34, no. 15, pp. 2317-2326, 2013.

[23] L. Zhang, Y. W. Lee, and D. Jahng, "Ammonia stripping for enhanced biomethanization of piggery wastewater," Journal of Hazardous Materials, vol. 199-200, pp. 36-42, 2012.

[24] V. K. Minocha and A. V. S. P. Rao, "Ammonia removal and recovery from urea fertilizer plant waste," Environmental Technology Letters, vol. 9, no. 7, pp. 655-664, 1988.

[25] L. Zhu, D. Dong, X. Hua, Z. Guo, and D. Liang, "Ammonia nitrogen removal from acetylene purification wastewater by air stripping," Water Science Technology, vol. 75, no. 11-12, pp. 2538-2545, 2017.

[26] Li Lin, J. Chen, Z. Q. Xu et al., "Removal of ammonia nitrogen in wastewater by microwave radiation: a pilot-scale study," Journal of Hazardous Materials, vol. 168, no. 2-3, pp. 862-867, 2009.

[27] M. Ellersdorfer, "The ion-exchange-loop stripping process: ammonium recovery from sludge liquor using NACl-treated clinoptilolite and simultaneous air stripping," Water Science and Technology, vol. 77, no. 3, pp. 695-705, 2017.

[28] J. H. La, T. Kim, J. K. Jang, and I. S. Change, "Ammonia nitrogen removal and recovery from swine wastewater by microwave radiation," Environmental Engineering Research, vol. 19, no. 4, pp. 381-385, 2014.

[29] A. Serna-Maza, S. Heaven, and C. J. Banks, "In situ biogas stripping of ammonia from a digester using a gas mixing system," Environmental Technology, vol. 38, no. 24, pp. 3216-3224, 2017.

[30] C. Collivignarelli, G. Bertanza, M. Baldi, and F. Avezzu, "Ammonia stripping from MSW landfill leachate in bubble reactors: process modelling and optimization," Waste Management \& Research, vol. 16, no. 5, pp. 455-466, 1998.

[31] K. Kojima, S. Zhang, and T. Hiaki, "Measuring methods of infinite-dilution activity coefficients and a database for systems including water," Fluid Phase Equilibria, vol. 131, no. 1-2, pp. 145-179, 1997.

[32] J. C. Campos, A. P. Moura, L. Costa, F. V. Yokoyama, D. F. Arouja, and M. C. Cammarota, "Evaluation of $\mathrm{pH}$, alkalinity and temperature during air stripping process for ammonia removal from landfill leachate," Journal of Environmental Science and Health, vol. 48, no. 9, pp. 1105-1113, 2013.

[33] D. Hidalgo, F. Corona, J. M. Martin-Marroquin, J. D. Alamo, and A. Alicia, "Resource recovery from anaerobic digestate: struvite crystallisation versus ammonia stripping," Desalination and Water Treatment, vol. 57, no. 6, pp. 2626-2632, 2015.
[34] G. Markou, M. Agriomallou, and D. Georgakakis, "Forced ammonia stripping from livestock wastewater. the influence of some physico-chemical parameters of the wastewater," Water Science \& Technlogy, vol. 75, no. 3-4, pp. 686-692, 2016.

[35] S. Gustin and R. Marinsek-Logar, "Effect of $\mathrm{pH}$, temperature and air flow rate on continuous ammonia stripping of the anaerobic digestion effluent," Process Safety and Environmental Protection, vol. 89, no. 1, pp. 1-66, 2011.

[36] P. Viotti and R. Gavasci, "Scaling of ammonia stripping towers in the treatment of groundwater polluted by municipal solid waste landfill leachate: study of the causes of scaling and its effects on stripping performance," Revista Ambient Agua, vol. 10, no. 2, pp. 241-252, 2015.

[37] C. T. Whitman, G. T. Mehan, G. H. Grubbs et al., "Development document for the proposed effluent limitations guidelines and standards for the meat and poultry products industry point source category," 2002, https://nepis.epa.gov/ Exe/ZyPDF.cgi/20002F0Q.PDF?.Dockey=20002F0Q.PDF.

[38] J. P. Maree and C. M. Zvinowanda, "Recovery of calcium carbonate from wastewater treatment sludge using a flotation technique," Journal of Chemical Engineering Process Technology, vol. 3, no. 2, pp. 1-6, 2012.

[39] K. L. He, S. B. Wu, L. C. Guo, Z. S. Ajmal, H. Z. Luo, and R. J. Dong, "Treatment of alkaline stripped effluent in aerated constructed wetlands: feasibility evaluation and performance enhancement," Water, vol. 8, no. 9, pp. 1-11, 2016.

[40] M. H. Yuan, Y. H. Chen, J. Y. Tsai, and C. Y. Chang, "Ammonia removal from ammonia-rich wastewater by air stripping using a rotating packed bed," Process Safety and Environmental Protection, vol. 102, pp. 777-785, 2016.

[41] X. J. Quan and Z. L. Cheng, "Mass transfer performance of a water-sparged aerocyclone reactor and its application in wastewater," Journal of Hazardous Materials, vol. 170, no. 2-3, pp. 983-938, 2009.

[42] N. Degermenci, O. N. Ata, and E. Yildiz, "Ammonia removal by air stripping in a semi-batch jet loop reactor," Journal of Industrial and Engineering Chemistry, vol. 18, no. 1, pp. 399-404, 2012.

[43] A. Behr and M. Becker, "Multiphase catalysis in jetloop-reactors," Chemical Engineering Transactions, vol. 17, pp. 141144, 2009.

[44] H.-J. Warnecke, M. Geisendorfer, and D. C. Hempel, "Mass transfer behaviour of gas-loop reactors," Acta Biotechnology, vol. 11, no. 1, pp. 306-311, 1988.

[45] K. H. Tebel and P. Zehner, "Fluid dynamic description of jet loop reactors in multiphase operation," Chemical Engineering Technology, vol. 12, no. 1, pp. 274-280, 1989.

[46] C. A. M. C. Dirix and K. Van de Wiele, "Mass transfer in jet loop reactors," Chemical Engineering Science, vol. 45, pp. 2333-2340, 1990.

[47] B. Farizoglu, B. Keskinler, E. Yildiz, and A. Nuhoglu, "Cheese whey treatment performance of anaerobic jet loop membrane bioreactor," Process Biochemistry, vol. 39, pp. 2283-2291, 2004.

[48] A. Eusobio, M. Petruccioli, M. Lageiro, F. Federici, and J. C. Duarte, "Microbial characterisation of activated sludge in jet-loop bioreactors treating winery wastewaters," Journal of Industrial Microbiology \& Biotechnology, vol. 31, no. 1, pp. 29-34, 2004.

[49] C. Matter-Muller, W. Gujer, and W. Giger, "Transfer of volatile subtances from water to the atmosphere," Water Research, vol. 15, no. 11, pp. 1271-1279, 1981.

[50] X. J. Quan, Z. L. Cheng, F. Xu, F. C. Qiu, D. Li, and Y. P. Yan, "Structural optimization of the porous section in a water-sparged 
aerocyclone reactor to enhance the air-stripping efficiency of ammonia," Journal of Environmental Chemical Engineering, vol. 2, no. 2, pp. 1199-1206, 2014.

[51] D. P. Rao, A. Bhowal, and P. S. Goswami, "Process intensification in rotating packed beds (HIGEE): an appraisal," Industrial Engineering Chemical Resource, vol. 43, no. 4, pp. 1150-1162, 2004.

[52] Y. Sun, T. Nozawa, and S. Furusaki, "Gas holdup and volumetric oxygen transfer coefficient in three-phase fluidized bed reactor," Journal of Chemical Engineering, vol. 21, no. 1, pp. 15-20, 1988.

[53] J. T. Xu, C. S. Liu, M. Wang et al., "Rotating packed bed reactor for enzymatic synthesis of biodiesel," Bioresource Technology, vol. 224, pp. 292-297, 2017.

[54] K. Guo, J. Wen, Y. Zhao et al., "Optimal packing of a rotating packed bed for H2S removal," Environmental Science \& Technology, vol. 48, no. 12, pp. 6844-6849, 2014.

[55] J. F. Chen, Y. H. Wang, F. Guo, X. M. Wang, and Z. Chong, "Synthesis of nanoparticles with novel technology: highgravity reactive precipitation," Industrial Engineering Chemistry Resource, vol. 39, no. 4, pp. 948-954, 2000.

[56] M. J. Semmens, D. M. Foster, and E. L. Cussler, "Ammonia removal from water using microporous hollow fibers," Journal of Membrane Science, vol. 51, no. 1-2, pp. 127-140, 1990.

[57] Y. T. Ahn, Y. H. Hwang, and H. S. Shin, "Application of PTFE membrane for ammonia removal in membrane contactor," Water Science and Technology, vol. 63, no. 12, pp. 2944-2948, 2011.

[58] A. Hasanoglu, J. Romero, B. Perez, and A. Plaza, “Ammonia removal from wastewater streams through membrane contactors: experimental and theoretical analysis of operation parameters and configuration," Chemical Engineering Journal, vol. 160 , no. 2, pp. 530-537, 2010.

[59] X. Y. Tan, S. P. Tan, W. K. Teo, and K. Li, "Polyvinylidene fluoride (PVDF) hollow fibre membranes for ammonia removal from water," Journal of Membrane Science, vol. 271, no. 1-2, pp. 59-68, 2006.

[60] Q. L. Liu, Z. H. Wang, L. W. Chen, and P. P. Wang, "The effect of ammonia initial concentration in membrane distillation process for high ammonia concentration wastewater treatment," in Proceedings of the International Conference on Consumer Electronics, Communications and Networks (CECNet), pp. 1795-1797, Beijing, China, March 2011.

[61] M. S. El-Bourawi, M. Khayet, R. Ma, Z. Ding, Z. Li, and $\mathrm{X}$. Zhang, "Application of vacuum membrane distillation for ammonia removal," Journal of Membrane Science, vol. 301, no. 1-2, pp. 200-209, 2007.

[62] L. Eykens, I. Hitsov, K. De Sitter, C. Dotremont, L. Pinoy, and B. V. D. Bruggen, "Direct contact and air gap membrane distillation: differences and similarities between lab and pilot scale," Desalination, vol. 422, pp. 91-100, 2017.

[63] Z. L. Xie, T. Duong, M. Hoang, N. Cuong, and B. Bolto, "Ammonia removal by sweep gas membrane distillation," Water Research, vol. 43, no. 6, pp. 1693-1699, 2009.

[64] Y. F. Liu, T. H. Xiao, C. H. Bao, J. F. Zhang, and X. Yang, "Performance and fouling study of asymmetric PVDF membrane applied in the concentration of organic fertilizer by direct contact membrane distillation," Membranes, vol. 8, no. 1, p. 9, 2018.

[65] A. G. Capodaglio, P. Hlavinek, and M. Raboni, "Physicochemical technologies for nitrogen removal wastewater: a review," Revista Ambiente Agua, vol. 10, no. 3, 2015.

[66] Q. Deng, B. R. Dhar, E. Elbeshbishy, and H. S. Lee, "Ammonium nitrogen removal from the permeates of anaerobic membrane bioreactors: economic regeneration of exhausted zeolite," Environmental Technology, vol. 35, no. 16, pp. 20082017, 2014.

[67] M. Ellersdorfer, "Recovery of ammonia from liquid digestate for NOx removal," in Proceedings of the 11th DepoTech Conference, vol. 835, pp. 367-372, Leoben, Austria, November 2012.

[68] O. N. Ata, A. Kanca, Z. N. Demir, and V. Yigit, “Optimization of ammonia removal from aqueous solution by microwaveassisted air stripping," Water Air Soil Pollition, vol. 228, no. 11, pp. 448-458, 2017.

[69] L. Le, H. W. Wang, and H. H. Lu, "Nitrogen removal using air stripping tower in urban wastewater treatment plant," China Wastewater, vol. 22, pp. 92-99, 2006.

[70] Q. Xia, Y. B. Yun, J. J. Chen, D. Qu, and C. L. Li, “Treatment of ammonia nitrogen wastewater by membrane distillation PVDF membrane," Desalination and Water Treatment, vol. 61, pp. 126-135, 2016.

[71] O. N. Ata, K. Aygun, H. Okur, and A. Kanca, "Determination of ammonia removal from aqueous solution and volumetric mass transfer coefficient by microave-assisted air stripping," International Journal of Science and Technology, vol. 13, no. 10, pp. 2459-2466, 2016.

[72] S. H. You, D. H. Tseng, and G. L. Guo, "A case study on the wastewater reclamation and reuse in the semiconductor industry," Resources, Conservation and Recycling, vol. 32, no. 1, pp. 73-81, 2001.

[73] M. Mulder, Basic Principal of Membrane Technology, Kluwer Academic Publisher, Norwell, MA, USA, 2nd edition, 1996.

[74] Y. Nishi and T. Inagaki, "Performance and flow field of gravitation vortex type water turbine," International Journal of Rotating Machinery, vol. 2017, Article ID 2610508, 11 pages, 2017. 


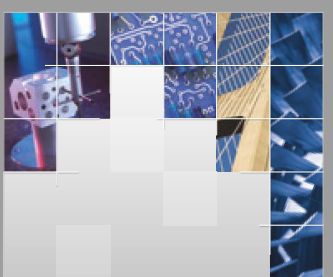

\section{Enfincering}
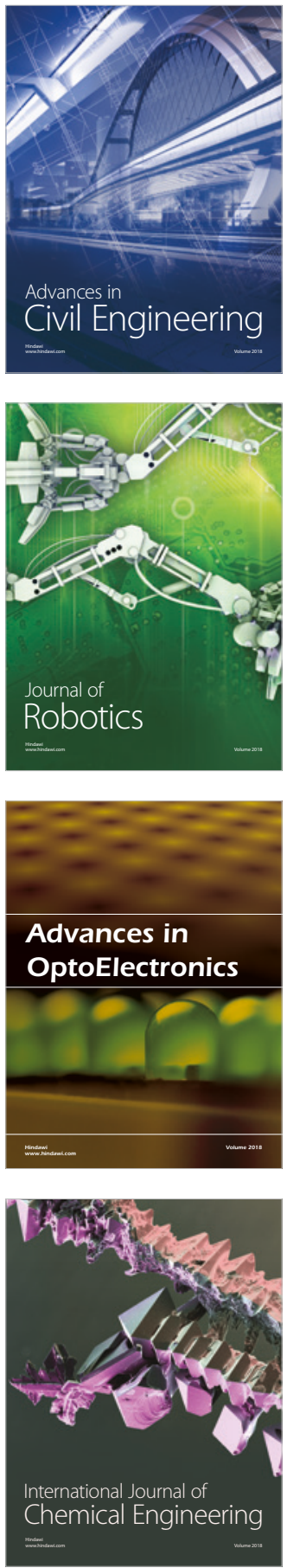

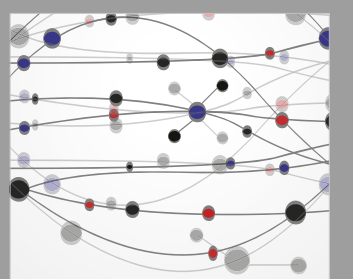

\section{Rotating \\ Machinery}

The Scientific World Journal

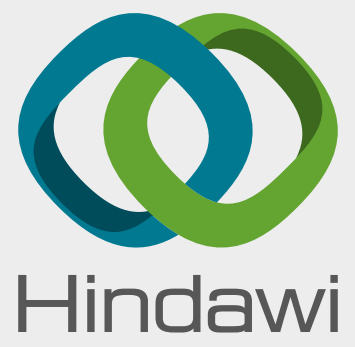

Submit your manuscripts at

www.hindawi.com
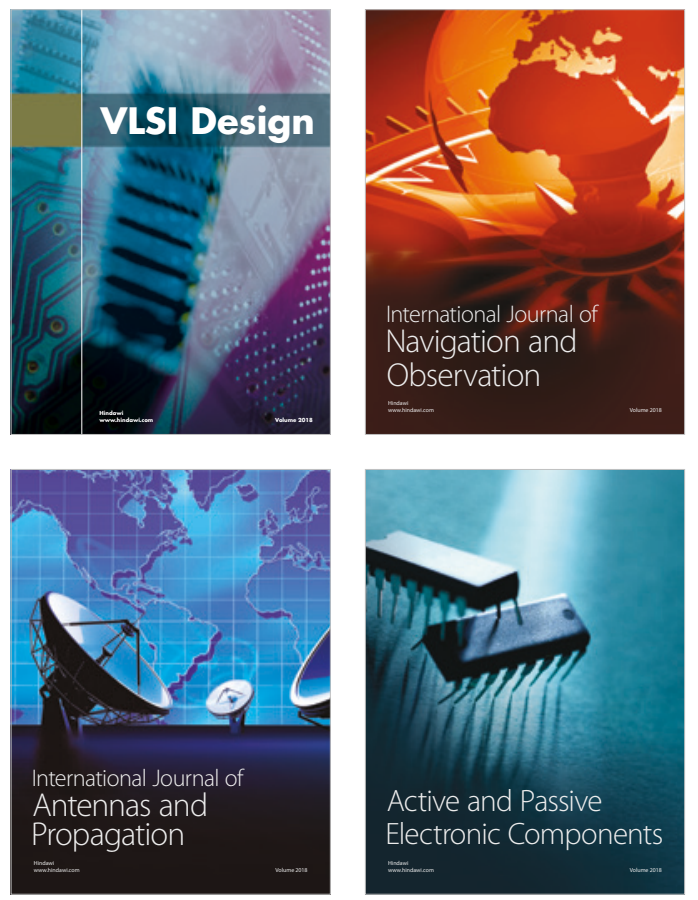
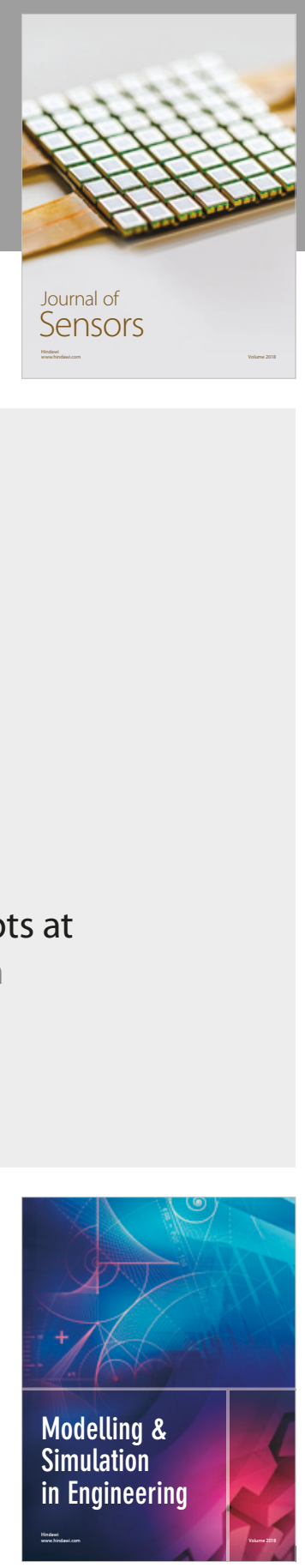

\section{Advances \\ Multimedia}
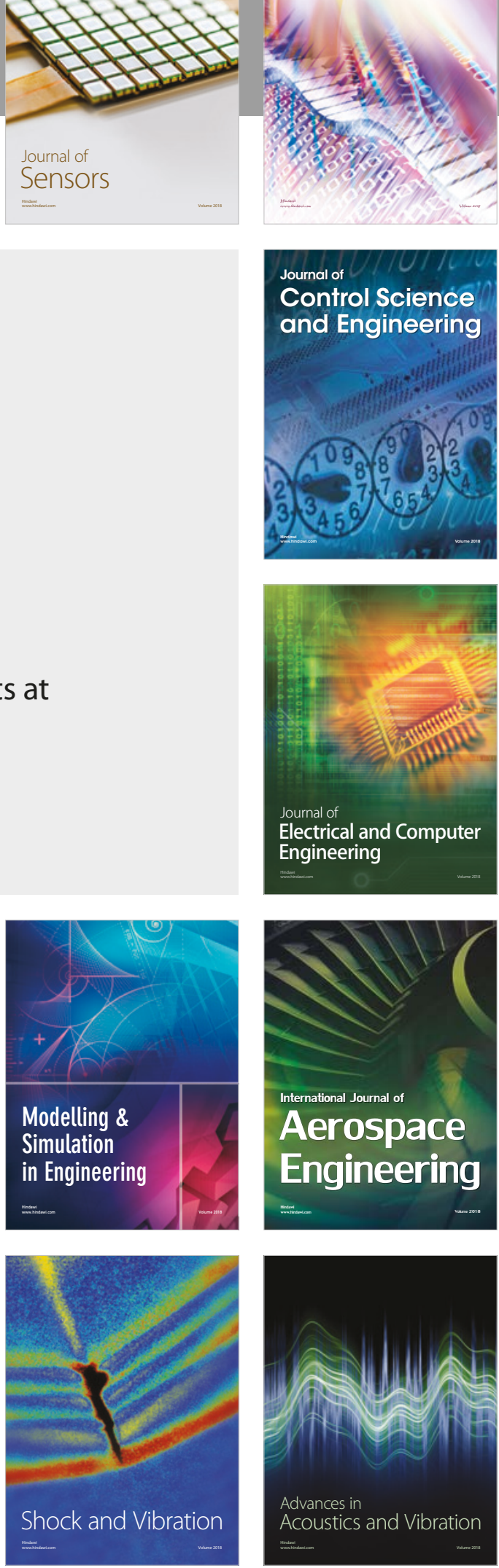